\title{
Premedication with Dexamethasone and Propofol to Control Fentanyl-Induced Cough
}

\author{
MUHAMMAD FAISAL FAROOQ ${ }^{1}$, HAIDER ALI KHAN², VIJAI KUMAR ${ }^{3}$, ARSALAN JAMIL ${ }^{4}$, SHAKIL MALIK ${ }^{5}$, \\ NAILA ZAHOOR ${ }^{6}$ \\ ${ }^{1}$ Assistant Professor, \\ 2,3,5 Senior Registrars, Department of Anesthesia, Sindh Institute of Urology and Transplantation Karachi \\ ${ }^{4}$ Senior Registrar, Department of Anesthesia, Aga Khan University Karachi \\ ${ }^{6}$ Assistant Professor, Department of Anesthesia, Baqai Medial University Karachi \\ Correspondence to Dr. Haider Ali Khan, E-mail: dr.h.khan@hotmail.com Cell 0331-9757570
}

\begin{abstract}
Background: Fentanyl-induced cough is a common difficulty encountered at induction of anesthesia. Various interventions both pharmacological and non-pharmacological have been used to prevent this side effect including dexamethasone and propofol.

Aim: To compare the effectiveness of dexamethasone and propofol to prevent fentanyl-induced cough at the induction of general anesthesia.

Study design: Randomized controlled trial.

Place and duration of study: Department of Anaesthesiology, Surgical ICU \& Pain Management, Dow University of Health Sciences and Civil Hospital Karachi from $16^{\text {th }}$ September 2011 to $15^{\text {th }}$ March, 2012.

Methodology: One hundred patients who underwent elective surgical procedure were selected. Patients were randomized in two groups of 50 patients each; Group D was given intravenous dexamethasone; whereas patients of group $P$ received intravenous propofol as the premedication before induction. The main outcome measure was effectiveness of both drugs to prevent fentanyl-induced cough.

Results: Majority of patients (40\%) were between $20-30$ years of age group with mean age was $35.80 \pm 10.14$ years. Males were more than females. Intravenous dexamethasone was significantly effective $(90 \%)$ than intravenous propofol $(70 \%)$ [ $\mathrm{p}=0.012]$.

Conclusion: Intravenous dexamethasone is effective in reducing fentanyl-induced cough in comparison to propofol.

Keywords: Dexamethasone, Propofol, Fentanyl-induced cough (FIC)
\end{abstract}

\section{INTRODUCTION}

Opioids including fentanyl a selective $\mu$-receptor agonist are commonly administered prior to general anesthesia to reduce pain and anxiety with its rapid onset, relatively shorter duration, potent analgesia, greater stability of hemodynamics and no release of histamine ${ }^{1}$. Reflex cough is often seen to occur in patients soon after IV bolus administration of fentanyl at the time of inducing general anesthesia.

Incidence of FIC have been reported vary between $28 \%$ to $65 \%$ in previously done studies. ${ }^{2}$ This may lead to intracranial, intraocular and intra-abdominal hypertension, which may have drastic results in already at risk patients. It has also been related to increase in incidence of postoperative nausea and vomiting ${ }^{3}$ and more drastically, it may lead a variety of periorbital and conjunctival ecchymosis and even severe obstruction of airway ${ }^{4,5}$. The side effects may be transit for most patients, but they may be arctic, drastic or even fatal for some ${ }^{6-8}$. There are several hypotheses for the mechanism of FIC, with no clear evidence ${ }^{9}$.

Dexamethasone, an intravenous steroid having strong anti inflammatory properties is being used before general anesthesia to prevent post operative nausea vomiting (PONV) and reported effective in preventing $\mathrm{FIC}^{10}$.

Received on 13-12-2020

Accepted on 21-04-2021
Dexamethasone and propofol have both been tried separately but their comparison however remains unclear. This will help develop guidelines for prevention of FIC without adding a new drug to anesthetics and by comparing the two the better choice can be advocated.

The cough suppressing effect of dexamethasone and propofol have been seen on FIC in two different studies with the incidence of was $6.3 \%$ in the group receiving dexamethasone ${ }^{11}$ and $40 \%$ in the group receiving propofol $^{10}$, it was reported in the study that the incidence of FIC appears to be lower in Europeans as compared to the Asians and since no published data is available for Pakistani population, so this study was conducted to compare the efficacy of dexamethasone and propofol to prevent FIC.

\section{MATERIALS AND METHODS}

This randomized controlled trial was conducted at the Department of Anaesthesiology, Surgical Intensive Care Unit and pain management, Dow University of Health Sciences and Civil Hospital Karachi from $16^{\text {th }}$ September 2011 to $15^{\text {th }}$ March 2012 and comprised 100 patients. They were divided in two groups; each group comprised 50 patients. Group D (dexamethasone) and 50 marked Group $P$ (propofol). At the time of induction of anesthesia the patient was allocated to either of the two groups, again by an assistant anesthetist not participating in the study via lottery method. The patients were also unaware of 
medications that will be used. The patients between 25 to 60 years of age with either gender, American Society of Anaesthesiologist (ASA) physical status I or II electively undergoing general surgical procedures under general anesthesia were included. While those with infection of upper respiratory tract in the last two weeks, cough for more than 2 months, asthmatic, or on drugs (taking angiotensin converting enzyme inhibitors, bronchodilators or steroids in last week) and those who were allergic to the study drugs were excluded. All patients were premedicated with midazolam $7.5 \mathrm{mg}$ orally one hour preoperatively .Intravenous cannulation was done with 18 gauge cannula and an intravenous crystalloid fluid was started at rate of $10 \mathrm{ml} / \mathrm{kg} / \mathrm{hr}$. According to the group of the patient as allocated the patients were given premedication of either dexamethasone or propofol. In those patients who were allocated to the dexamethasone group (group D), $10 \mathrm{mg}$ of dexamethasone was given intravenously while those who were assigned to the propofol group (group P) received propofol $1 \%, 1 \mathrm{mg} / \mathrm{kg}$ intravenously. In both the groups this was followed by the administration of intravenous $2 \mu \mathrm{g} / \mathrm{kg}$ fentanyl as a bolus after 1 minute. This bolus was infused over two seconds in all the patients of either group.

After administration of fentanyl, all the patients in both groups were observed for the period of one minute for number of episodes of cough. The severity of cough was graded over a scale of 0 to 3 according to the number of episodes of cough. The data was recorded by an anesthesia resident (post graduate year 3 and 4), not participating in the study. During this period, preoxygenation was done with $100 \%$ oxygen and continued for five minutes, after which anesthesia was induced as per routine. Patient was then manually ventilated and anesthesia was maintained with isoflurane $1 \%$ in combination with $60 \%$ Nitrous Oxide and $40 \%$ oxygen. The severity of cough of grade 0 that is no cough was considered as effective and was taken as the main outcome variable. The data was entered and analyzed through SPSS-20. The effectiveness of dexamethasone in preventing fentanyl-induced cough was compared with propofol through Chi square test. A p-value of less than 0.05 was considered significant.

\section{RESULTS}

Table 1: Frequency of effective cases

\begin{tabular}{|l|c|c|}
\hline Variable & Group D & Group P \\
\hline \multicolumn{1}{|c|}{ Age (years) [n=80] } & $25(31.3 \%)$ & $7(8.7 \%)$ \\
\hline $20-30$ & $10(12.5 \%)$ & $2(2.5 \%)$ \\
\hline $31-40$ & - & $26(32.5 \%)$ \\
\hline $41-50$ & $10(12.5 \%)$ & - \\
\hline $51-60$ & $25(31.3 \%)$ & $19(23.7 \%)$ \\
\hline Gender (n=80) & $20(25 \%)$ & $16(20 \%)$ \\
\hline Male & $21(26.3 \%)$ & $19(23.7 \%)$ \\
\hline Female & $24(30 \%)$ & $16(20 \%)$ \\
\hline ASA class (n=80) & $16(40 \%)$ \\
\hline I & $14(35 \%)$ & - \\
\hline II & $10(25 \%)$ & \\
\hline Co-morbidities (n=40) & \\
\hline Diabetes & \multicolumn{2}{|l|}{} \\
\hline Hypertension & \multicolumn{2}{|l|}{} \\
\hline
\end{tabular}

Table 2: Distribution of severity among groups $(n=100)$

\begin{tabular}{|l|c|c|}
\hline Severity & Group D & Group P \\
\hline Grade 0 & $45(90 \%)$ & $35(70 \%)$ \\
\hline Grade 1 & $3(6 \%)$ & $10(20 \%)$ \\
\hline Grade 2 & $2(4 \%)$ & $4(8 \%)$ \\
\hline Grade 3 & - & $1(2 \%)$ \\
\hline
\end{tabular}

Table 3: Comparison of effectiveness among groups $(n=100)$

\begin{tabular}{|l|c|c|}
\hline Effectiveness & Group D & Group P \\
\hline Yes & $45(90 \%)$ & $35(70 \%)$ \\
\hline No & $5(10 \%)$ & $15(30 \%)$ \\
\hline P value & \multicolumn{3}{|c|}{0.012} \\
\hline
\end{tabular}

Mean ages in group $D$ and $P$ were $33.60 \pm 12.36$ years and $38.0 \pm 6.70$ years respectively while the overall mean weight was $59.60 \pm 9.77$ kilograms. (Table 1) Patients who received dexamethasone had a lower severity grade of cough (Table2) and higher effectiveness as compared to propofol (Table 3). Out of the 50 patients who received dexamethasone, 45 patients $(90 \%)$, had no cough while in those patients who received propofol, effectiveness was seen in $70 \%$ of the patients (35 patients) $[p=0.012]$.

\section{DISCUSSION}

Fental-induced cough was effectively prevented with pretreatment with dexamethasone in $90 \%$ of our patients as compared to propofol which was effective in $70 \%$ of our patients. Both the drugs in our study were given just $1 \mathrm{~min}$ before the bolus of fentanyl, unlike the previous studies ${ }^{11}$, which allowed more time for pretreatment to effect, further more we also didn't take more than 30 seconds to inject fentanyl which it-self would decrease the incidence of $\mathrm{FIC}^{12}$. There were no incidence of significant hemodynamic changes with either of the studied drugs at the time of induction.

Even though there are several hypothesis and still the mechanism of FIC is unknown. Different drugs have been studied on FIC with resulted in variable reduction in incidences of FIC .While some physical factors like age ${ }^{13}$, ethnicity ${ }^{14}$ and history of smoking ${ }^{15}$ may also effect FIC. It has been studied that Asian people are more sensitive to fentanyl and its analogs. ${ }^{15}$ Even though we didn't include children in our study, the youngest group of patients were resistant to the effect of our preventive drugs, but overall this was not so significant.

A meta-analysis done by Shuying et $\mathrm{al}^{16}$ found lidocaine to be the most effective opioid induced cough suppression, may be because of its inhibition of central brain stem and peripheral cough receptors, but unlike dexamethasone it may be associated with arrhythmias and may potentiate cardiovascular depression during induction of anaesthesia ${ }^{17}$. Ketamine ${ }^{18,19}$, dexmedetomidine ${ }^{20}$ were also found to be effective in studies but they had complications. Hallucinations, intracranial hypertension, intraocular hypertension, and increased blood pressures were seen with ketamine while hypotension and bradycardia was observed with dexmedetomidine ${ }^{20}$.

Although sedation and CNS inhibition is a well known effect of propofol ${ }^{21}$ and it should had have a more preventative action than dexamethasone, but our results 
show otherwise this could be because dexamethasone may have activate neutral endopeptidase which in turn, would have depress the reactivity through airway epithelial cells ${ }^{22}$.

The primary limitation of our study was, it was not a blinded study. Even though we tried to limit the biasness by a separate observer that was not involved in the study but this may have lead to over estimation of preventive effects of dexamethasone. Another factor that we did not consider was the total propofol or other induction drugs used in induction of anesthesia in the group $\mathrm{P}$, as premedication with propofol may reduce the requirement of the drug needed to induce anesthesia and may be a future study could be done in this aspect there by eliminating the need of additional prophylactic drug.

\section{CONCLUSION}

$10 \mathrm{mg}$ intravenous dexamethasone is more effective in reducing fentanyl-induced cough in comparison to propofol.

\section{REFERENCES}

1. Zhou W, Zhang D, Tian S, Yang Y, Xing Z, Ma R, et al. Optimal dose of pretreated-dexmedetomidine in fentanylinduced cough suppression: a prospective randomized controlled trial. BMC Anesthesiol 2019;19(1):1-7.

2. Gupta P, Jindal P, Kumar N. Role of pre-emptive Huff's manoeuvre and acupressure in reducing the incidence of fentanyl induced cough; a risk factor for postoperative nausea vomiting in female patients: a prospective randomised controlled study. Indian J Anaesthesia 2019;63(10):834.

3. Li CC, Chen SS, Huang CH, Chien KL, Yang HJ, Fan SZ, et al. Fentanyl-induced cough is a risk factor for postoperative nausea and vomiting. Br J Anaesthesia 2015;115(3):444-8.

4. Gu C, Zhou M, Wu H, Li F, Tang Q. Effects of different priming doses of fentanyl on fentanyl-induced cough: a double-blind, randomized, controlled study. Pharmacol Reports 2012;64(2):321-5.

5. Liu M, Li Z, Wang S, Liu Y, Zhong X, He R, Li F. Application via mechanical dropper alleviates sufentanil-induced cough: a prospective, randomized, single-blinded trial. Trials 2019;20(1):1-7.

6. Dahan A, Aarts L, Smith TW. Incidence, reversal, and prevention of opioid-induced respiratory depression. J Am Soc Anesthesiol 2010;112(1):226-38.

7. Tweed WA, Dakin D. Explosive coughing after bolus fentanyl injection. Anesthesia Analgesia 2001;92(6):1442-3.

8. Lim KJ, Lee SK, Lee HM, Park EY, Kim MH, Kim YS, et al. Aspiration pneumonia caused by fentanyl-induced cough-a case report. Korean J Anesthesiol 2013;65(3):251.

9. Meng Q, Chen R, Tang L, Sun T, Zeng Z, Zhang Y, Ding K. Mechanism and management of fentanyl-induced cough. Frontiers Pharmacol 2020;11:1691.
10. Tang Q, Qian Y, Zhang Q, Yang J, Wang Z. Effects of different priming doses of propofol on fentanyl-induced cough during anesthesia induction: a preliminary randomized controlled study. Upsala journal of medical sciences. 2010 May $1 ; 115(2): 121-4$.

11. Lin JA, Chen FC, Lee MS, Horng HC, Cherng CH, Yeh CC, et al. Intravenous dexamethasone pretreatment reduces fentanyl-induced cough. J Formosan Med Assoc 2007;106(8):649-55.

12. El Baissari MC, Taha SK, Siddik-Sayyid SM. Fentanylinduced cough-pathophysiology and prevention. Middle East J Anaesthesiol 2014; 22(5):449-56.

13. Golmohammadi M, Shajiee S, Sane S, Valie M. Comparison of the effects of pretreatment intravenous fentanyl or intravenous lidocaine on suppression of fentanyl-induced cough in children: a randomized, double-blind, controlled clinical trial. Electronic Physician 2018; 10(6):6877.

14. Schäpermeier U, Hopf HB. Fentanyl-induced cough does not depend on injection speed: a randomized study. Acta Anaesthesiologica Scandinavica 2008;52(8):1071-5.

15. Lin JA, Yeh CC, Lee MS, Wu CT, Lin SL, Wong CS. Prolonged injection time and light smoking decrease the incidence of fentanyl-induced cough. Anesthesia Analgesia 2005; 101(3):670-4.

16. Shuying L, Ping L, Juan N, Dong L. Different interventions in preventing opioid-induced cough: a meta-analysis. J Clin Anesthesia 2016;34:440-7.

17. Said SI, Berisha HI, Pakbaz H. N-methyl-D-aspartate receptors outside the central nervous system: activation causes acute lung injury that is mediated by nitric oxide synthesis and prevented by vasoactive intestinal peptide. Neuroscience 1995;65:943-6.

18. Sato T, Hirota K, Matsuki A, Zsigmond EK, Rabito SF. The role of the $\mathrm{N}$-methyl-D-aspartic acid receptor in the relaxant effect of ketamine on tracheal smooth muscle. Anesth Analg 1998;87:1383-8.

19. Zhou W, Zhang D, Tian S, Yang Y, Xing Z, Ma R, et al. Optimal dose of pretreated-dexmedetomidine in fentanylinduced cough suppression: a prospective randomized controlled trial. BMC Anesthesiol 2019;19(1):1-7.

20. Kaur M, Singh PM. Current role of dexmedetomidine in clinical anesthesia and intensive care. Anesthesia Essays Res 2011; 5(2):128.

21. Trapani GM, Altomare C, Sanna E, Biggio G, Liso G. Propofol in anesthesia. Mechanism of action, structure-activity relationships, and drug delivery. Curr Med Chem 2000;7(2):249-71.

22. Lang Z, Murlas CG. Neutral endopeptidase of a human airway epithelial cell line recovers after hypochlorous acid exposure: dexamethasone accelerates this by stimulating neutral endopeptidase mRNA synthesis. Am J Resp Cell Molecular Biol 1993;7:300. 